\title{
Maternal plasma sequencing: a powerful tool towards fetal whole genome recovery
}

\author{
Elisavet A Papageorgiou ${ }^{1,2}$ and Philippos C Patsalis ${ }^{2^{*}}$
}

Please see related article: http://genomemedicine.com/content/5/2/18

\begin{abstract}
Noninvasive prenatal diagnosis of chromosomal aneuploidies, although challenging, has been achieved through the implementation of novel methodologies such as methylated DNA immunoprecipitation and next generation sequencing technologies. Nevertheless, additional developments are required towards the interpretation of other fetal abnormalities of higher complexity, such as de novo mutations including microdeletion and microduplication syndromes as well as complex diseases. The application of next generation sequencing technologies towards fetal whole genome recovery has demonstrated great potential to achieve the above goal. In a research article published in Genome Medicine, Chen et al. presented a novel approach that allowed more robust and accurate characterization of parental alleles compared with previous studies. This was achieved through a revolutionary strategy based on the use of trios and unrelated individuals that simultaneously targets the interpretation of the fetal haplotype and phenotype in one step. It is hereby shown that the implementation of a more accurate experimental design in combination with proper analytical tools can provide robust noninvasive fetal whole genome recovery with the potential for further developments beyond the DNA level.
\end{abstract}

Keywords: Fetal whole genome recovery, next generation sequencing, noninvasive prenatal diagnosis

\footnotetext{
* Correspondence: patsalis@cing.ac.cy

${ }^{2}$ The Cyprus Institute of Neurology and Genetics, PO Box 23462, 1683, Nicosia, Cyprus

Full list of author information is available at the end of the article
}

\section{Introduction}

The implementation of noninvasive prenatal diagnosis (NIPD) for chromosomal aneuploidies has been one of the most fascinating achievements for the scientific world because it can offer a safer diagnosis for the fetus after just 10 weeks of gestation [1-7]. Although the challenges associated with the development of NIPD for common aneuploidies have been overcome, the field of NIPD lies beyond the need for prenatal diagnosis of common aneuploidies. Further expansion is required towards the exploitation and diagnosis of other fetal abnormalities that are subtle, infrequent and are not restricted to copy number changes. The implementation of next generation sequencing technologies in the development of NIPD has revolutionized the field and has provided new insight towards further expansion of NIPD. In 2010, the possibility of using next generation sequencing technologies towards whole genome fetal recovery was described for the first time [8]. More recent studies have supported the initial finding, providing new perspectives in the field of NIPD $[9,10]$.

In a research article published in Genome Medicine, Chen et al. presented a novel approach to NIPD that allowed more robust and accurate characterization of parental alleles compared with previous studies [11]. We here aim to address the advantages of the methodology applied by Chen et al. compared with previously developed methodologies towards noninvasive whole genome fetal recovery. Furthermore, we discuss the potential for future developments of the approach proposed by Chen et al.

\section{Noninvasive prenatal diagnosis for screening fetal abnormalities}

The need for further developments towards prenatal diagnosis of other fetal abnormalities, including Mendelian diseases as well as complex diseases, has led to the development of technologies towards noninvasive fetal whole genome recovery. The application of next
() Biomed Central

(c) 2013 Papageorgiou and Patsalis; licensee BioMed Central Ltd. This is an Open Access article distributed under the terms of the Creative Commons Attribution License (http://creativecommons.org/licenses/by/2.0), which permits unrestricted use, distribution, and reproduction in any medium, provided the original work is properly cited. 
generation massively parallel sequencing has shown to be a very promising approach that would allow extensive investigation of the fetal genome [8-10]. Nevertheless, the approaches described so far are not free of limitations and challenges, and require further investigation and improvement. Chen et al. introduced a novel approach towards noninvasive whole genome fetal recovery that overcomes a large number of limitations associated with previously developed methodologies.

Previous studies have focused on inferring the fetal genotype based on a maternal haplotype-assisted approach with no additional interest in the characterization of the biparental heterozygous sites in the fetal genome. As a consequence, there is an uncertainty regarding the accuracy of paternal allele recovery. Chen et al. introduced a novel approach for fetal genome recovery that takes into account the paternal allele transition in maternal plasma [11]. This strategy has allowed the assessment of both fetal genotype and fetal phenotype simultaneously and in one step. They used, for the first time, a combined strategy of trios and unrelated individuals to construct parental haplotypes. This allowed a more robust investigation of the fetal genome compared with previous studies that have used only trios $[9,10]$.

Although previous studies have achieved accurate whole genome fetal recovery, their technology is restricted by the limited cell-free fetal DNA (cffDNA) concentration present in maternal plasma, which allowed only the assessment of cases that had a cffDNA concentration $>6 \%$ [10]. One of the most important characteristics of the strategy developed by Chen et al. is that it allows the reconstruction of the fetal genome irrespective of the cffDNA concentration and sequence depth. This strategy led to $100 \%$ maternal and paternal allele recovery in contrast to previous methodologies, which were only able to achieve a recovery rate $>91.4 \%$ for maternal and $71.60 \%$ to $72.94 \%$ for paternal alleles $[9,10]$. This is the first time that such a high recovery rate has been achieved, demonstrating the importance and the need for a combined genotype-haplotype approach, as the haplotype information is essential for complex diseases screening and identification of fetal de novo copy number variations, including microdeletion and microduplication syndromes.

\section{Analysis pipeline}

It is of great interest to evaluate the analysis pipeline applied by Chen et al. compared with that applied by other groups. Previous studies have implemented a siteby-site strategy to determine the paternal-specific allele [10], occasionally in combination with population-scale sequencing data [9]. However, the above approaches retrieved only $60.3 \%$ to $70 \%$ of paternal-specific alleles. These results impose the inaccuracy of using only a site- by-site strategy approach in minute amounts of cffDNA and in low sequencing read depth.

Chen et al. have revolutionized the field by introducing a new strategy in which a combination of analytical tools were applied to reveal both the haplotype and genotype of the fetus, in contrast to previous studies that focus on the fetal genotype inference [11]. Fetal haplotype recovery was achieved by using the parental haplotypes obtained by the genetic analysis software BEAGLE (a software package for analysis of large-scale genetic data sets with hundreds of thousands of markers genotyped on thousands of samples) for both parental genotype and grandparents' genotyping data in combination with data obtained from the trio study of the Han Chinese 1000 Genomes Project (pilot II) [12]. They managed to achieve fetal whole genome recovery in one step, with $100 \%$ recovery of the paternal allele and characterization of recombination breakpoints, by using the site-by-site strategy approach along with the Hidden Markov Mode and Viterbi algorithm.

\section{Future directions and conclusions}

The strategy developed by Chen et al. aimed to recover both fetal haplotype and genotype in one step. They used, for the first time, trios in combination with unrelated individuals and achieved a more accurate characterization of parental haplotypes, reaching a predicted rate of $100 \%$. It is clear that this novel approach will facilitate a broader scope in the field of NIPD, including the characterization of Mendelian diseases, the screening of complex diseases and the identification of de novo copy number changes, including microdeletion and microduplication syndromes. Although further developments are still required for more accurate fetal de novo mutation detection, the Chen et al. study has demonstrated the dynamics associated with the use of three generations of a family, which can potentially lead to the more robust identification of both rare and common mutations in the fetal genome.

Moreover, this study demonstrated an increase in accuracy, especially for paternal allele recovery, even in cases with a limited amount of cffDNA $(>6 \%)$ and at lower sequence depth. This information is of great importance because the technology will not be limited to early gestation, in contrast to previously developed methodologies.

Accurate and robust noninvasive fetal whole genome recovery will also offer solutions at different levels, such as the DNA level (for example, microdeletions, microduplications and point mutations), the level of epigenetic modifications (for example, methylation and chromatin) as well as the translational level (for example, mRNA and microRNAs). Nevertheless, further experimental designs and analytical tool developments are required to decipher such complex information. 
Although the current cost for next generation sequencing - especially at the magnitude of whole genome recovery, - is restrictive, it is expected that further technology developments will reduce the cost and will provide more applicable approaches with short turnaround times for noninvasive fetal whole genome recovery.

\section{Authors' contributions}

EAP prepared the manuscript and PCP contributed to the final revisions. Both authors read and approved the final manuscript.

\section{Authors' information}

PCP is the Chief Executive Medical Director of the Cyprus Institute of Neurology and Genetics, Cyprus. EAP is the Chief Scientific Officer at NIPD Genetics Ltd. and a Visiting Scientist of the Cyprus Institute of Neurology and Genetics.

\section{Competing interests}

PCP and EAP have filled a Patent Cooperation Treaty patent application for a novel NIPD approach for Down syndrome (PCT Patent Application No. PCT/ 1B2011/000217) and have extensive experience in the field of NIPD. PCP and EAP are co-founders of NIPD Genetics Ltd in Cyprus. The company aims to commercialize a MeDIP real-time $\mathrm{qPCR}$-based approach that PCP and EAP have developed for the NIPD of Down syndrome.

\section{Acknowledgements}

No funding body was involved for the preparation of this manuscript.

\section{Author details}

${ }^{1}$ NIPD Genetics Ltd, PO Box 27954, 2434, Nicosia, Cyprus. ${ }^{2}$ The Cyprus Institute of Neurology and Genetics, PO Box 23462, 1683, Nicosia, Cyprus.

Received: 18 February 2013 Accepted: 27 February 2013

Published: 27 February 2013

\section{References}

1. Papageorgiou EA, Karagrigoriou A, Tsaliki E, Velissariou V, Carter NP, Patsalis PC: Fetal specific DNA methylation ratio permits non-invasive prenatal diagnosis of trisomy 21. Nat Med 2011, 17:510-513.

2. Patsalis $P C$, Tsaliki $E$, Koumbaris $G$, Karagrigoriou A, Velissariou $V$, Papageorgiou EA: A new non-invasive prenatal diagnosis of Down syndrome through epigenetic markers and real-time qPCR. Expert Opin Biol Ther 2012, 12(Suppl 1):S155-161.

3. Tsaliki E, Papageorgiou EA, Spyrou C, Koumbaris G, Kypri E, Kyriakou S, Sotiriou C, Touvana E, Keravnou A, Karagrigoriou A, Lamnissou K, Velissariou V, Patsalis PC: MeDIP real-time qPCR of maternal peripheral blood reliably identifies trisomy 21. Prenat Diagn 2012, 32:996-1001.

4. Chiu RW, Akolekar R, Zheng YW, Leung TY, Sun H, Chan KC, Lun FM, Go AT, Lau ET, To WW, Leung WC, Tang RY, Au-Yeung SK, Lam H, Kung YY, Zhang $X$, van Vugt JM, Minekawa R, Tang MH, Wang J, Oudejans CB, Lau TK, Nicolaides KH, Lo YM: Non-invasive prenatal assessment of trisomy 21 by multiplexed maternal plasma DNA sequencing: large scale validity study. BMJ 2011, 342:C7401.

5. Chiu RW, Sun H, Akolekar R, Clouser C, Lee C, McKernan K, Zhou D, Nicolaides KH, Lo YM: Maternal plasma DNA analysis with massively parallel sequencing by ligation for noninvasive prenatal diagnosis of trisomy 21. Clin Chem 2010, 56:459-463.

6. Ehrich M, Deciu C, Zwiefelhofer T, Tynan JA, Cagasan L, Tim R, Lu V, McCullough R, McCarthy E, Nygren AO, Dean J, Tang L, Hutchison D, Lu T, Wang H, Angkachatchai V, Oeth P, Cantor CR, Bombard A, van den Boom D: Noninvasive detection of fetal trisomy 21 by sequencing of DNA in maternal blood: a study in a clinical setting. Am J Obstet Gynecol 2011, 204:205.e1-11.

7. Palomaki GE, Kloza EM, Lambert-Messerlian GM, Haddow JE, Neveux LM, Ehrich M, van den Boom D, Bombard AT, Deciu C, Grody WW, Nelson SF, Canick JA: DNA sequencing of maternal plasma to detect Down syndrome: an international clinical validation study. Genet Med 2011, 13:913-920.
8. Lo YM, Chan KC, Sun H, Chen EZ, Jiang P, Lun FM, Zheng YW, Leung TY, Lau TK, Cantor CR, Chiu RW: Maternal plasma DNA sequencing reveals the genome-wide genetic and mutational profile of the fetus. Sci Trans/ Med 2010, 2:61ra91.

9. Fan HC, Gu W, Wang J, Blumenfeld YJ, El-Sayed YY, Quake SR: Non-invasive prenatal measurement of the fetal genome. Nature 2012, 487:320-324.

10. Kitzman JO, Snyder MW, Ventura M, Lewis AP, Qiu R, Simmons LE, Gammill HS, Rubens CE, Santillan DA, Murray JC, Tabor HK, Bamshad MJ, Eichler EE, Shendure J: Noninvasive whole-genome sequencing of a human fetus. Sci Transl Med 2012, 4:137ra176.

11. Chen S, Ge H, Wang X, Pan X, Yao X, Li X, Zhang C, Chen F, Jiang F, Li P, Jiang $H$, Zheng $H$, Zhang L, Zhao L, Wang W, Wang J, Yang H, Li Y, Zhang $X$ : Haplotype-assisted accurate noninvasive fetal whole genome recovery through maternal plasma sequencing. Genome Medicine 2013.

12. 1000 Genomes. A Deep Catalog of Human Genetic Variation. [http:// www.1000genomes.org/]

Pre-publication history

The pre-publication history for this paper can be accessed here: http://www.biomedcentral.com/1741-7015/11/56/prepub

doi:10.1186/1741-7015-11-56

Cite this article as: Papageorgiou and Patsalis: Maternal plasma sequencing: a powerful tool towards fetal whole genome recovery. $B M C$ Medicine 2013 11:56.

\section{Submit your next manuscript to BioMed Central and take full advantage of:}

- Convenient online submission

- Thorough peer review

- No space constraints or color figure charges

- Immediate publication on acceptance

- Inclusion in PubMed, CAS, Scopus and Google Scholar

- Research which is freely available for redistribution

Submit your manuscript at www.biomedcentral.com/submit
Ciomed Central 